\title{
Overexpression of CCDC34 in colorectal cancer and its involvement in tumor growth, apoptosis and invasion
}

\author{
WEI GENG, WEI LIANG, YANAN FAN, ZHIBIN YE and LIXIAO ZHANG \\ Department of General Surgery, Hebei General Hospital, Shijiazhuang, Hebei 050051, P.R. China
}

Received January 5, 2017; Accepted August 3, 2017

DOI: $10.3892 / \mathrm{mmr} .2017 .7860$

\begin{abstract}
It has been previously reported that increased expression of coiled-coil domain containing 34 (CCDC34), a member of the CCDCs family, may promote the proliferation and invasion of bladder cancer cells. However, its role in colorectal cancer (CRC) remains unclear. The present study investigated CCDC34 expression in CRC tissues and determined the association between CCDC34 expression and biological characteristics in patients with CRC. Additionally, the variation of cell activity, apoptosis, invasion and associated mechanisms were evaluated following CCDC34 inhibition in SW620 cells with small interfering RNA (siRNA). The role of CCDC34 in CRC growth, apoptosis and invasion was investigated. In the current study, immunohistochemistry revealed an overexpression of CCDC34 in CRC tissues compared with paracancerous tissue $\left(\chi^{2}=29.810 ; \mathrm{P}<0.001\right)$. Furthermore, CCDC34 expression was revealed to be associated with tumor invasion depth and lymphatic metastasis $\left(\chi^{2}=4.343, \mathrm{P}=0.037 ; \chi^{2}=7.915\right.$, $\mathrm{P}=0.005)$. Additionally, the inhibition of CCDC34 expression in SW620 cells led to reduced tumor cell activity, increased apoptosis rate and reduced invasion ability, and expression of apoptosis and invasion-associated genes varied simultaneously which demonstrated that B cell leukemia/lymphoma 2, survivin, N-cadherin, and MMP-9 were decreased, whereas E-cadherin increased significantly in cells of CCDC34-siRNA group compared with the control group $(\mathrm{P}<0.05)$. Therefore, CCDC34 may contribute to CRC development by inhibiting apoptosis of cancer cells and promoting invasion.
\end{abstract}

\section{Introduction}

Colorectal cancer (CRC) is one of the most common malignant cancers worldwide (1), with considerable medical cost to society and suffering of patients with CRC $(2,3)$. As CRC is

Correspondence to: Dr Wei Geng, Department of General Surgery, Hebei General Hospital, 348 Heping West Road, Shijiazhuang, Hebei 050051, P.R. China

E-mail: gengweisur@sina.com

Key words: colorectal cancer, coiled-coil domain containing 34, pathology parameters, gene interference, apoptosis, invasion characterized by rapid progression, majority of patients are diagnosed with advanced stage at the first hospital visit and cannot undergo operation to remove tumor (4). Patients that have had the tumor removed surgically, still have high risk of recurrence and metastasis postoperatively $(5,6)$ due to rapid growth (7), resistance to apoptosis (8) and invasion of CRC tumor cells (9). Thus, it is important to identify the genes relevant to regulation of apoptosis and invasion of CRC cells to improve the diagnosis and comprehensive treatments for CRC.

Coiled-coil domain containing (CCDC) proteins, one family of protein with coiled-coil structures, possess a wide range of physiological functions (10), and the potential associations between some members of CCDC family and cancers have been previously reported. Previous studies have confirmed that CCDC67, CCDC6 and CCDC134 were associated with apoptosis and invasion of thyroid, lung and stomach cancer cells (11-14). CCDC34 is also a member of CCDC family, and has been reported to contribute to apoptosis and invasion of bladder cancer cells (15); however, it is currently uncertain whether CCDC34 can exacerbate this process in CRC cells. In the current study, the expression of CCDC34 protein in paraffin-embedded tissue samples was detected and clinical pathological data of patients with CRC was also collected. The association between CCDC34 expression and the biological characteristics of patients with CRC was analyzed. Additionally, endogenous CCDC34 expression in SW620 cells was suppressed with small interfering RNA (siRNA) and the changes of cell metabolic activity, apoptosis and invasion ability were detected following the siRNA transfection. Subsequently, reverse-transcription quantitative polymerase chain reaction (RT-qPCR) and western blotting was used to detect the expression levels of apoptosis and invasion-associated genes, including B cell leukemia/lymphoma 2 (Bcl-2), survivin, E-cadherin, N-cadherin and matrix metallopeptidase-9 (MMP-9) after endogenous CCDC34 in CRC cells was inhibited. The current findings suggested that the detection of CCDC34 may be valuable for the evaluation of patients with $\mathrm{CRC}$ and provided evidence for the investigation of its role in invasion and metastasis of CRC.

\section{Materials and methods}

Patients and tissue specimens. In the current study, a total of 85 paraffin specimens of tumor tissues were obtained from 
patients with CRC diagnosed and received surgical treatment at Hebei General Hospital (Shijiazhuang, China) between January 2015 and June 2016. In addition, 60 paraffin specimens of paracancerous tissues were selected as controls, which were $>3 \mathrm{~cm}$ from edge of cancer and no cancer cells were observed with microscopic examination. In total, 59 male patients and 26 female patients were recruited, and the patients aged from 41-76 (mean age, 57.29 \pm 7.49). All enrolled patients did not suffer from other cancers and were pathologically confirmed as adenocarcinoma with no preoperative treatments such as radiotherapy, chemotherapy or targeted therapy. The current study has been approved by the Medical Ethics Committee of Hebei General Hospital and informed consent was obtained from all participants.

Cell lines and reagents. HCT8, HCT116, SW620, SW480, LS-174T, HT29 human colon cancer cell lines were purchased from the Cell Resource Centre of Shanghai Institutes for Biological Sciences, Chinese Academy of Sciences (Shanghai, China), and passaged and preserved in Hebei General Hospital. Cells after 5-8 passages were used for the study. Rabbit anti-human polyclonal antibodies against CCDC34 (SAB1303750) were from Sigma-Aldrich; Merck KGaA (Darmstadt, Germany), and antibodies against Bcl-2 (sc-783), survivin (sc-10811), E-cadherin (sc-7870), N-cadherin (sc-7939), MMP-9 (sc-10737) and $\beta$-actin (sc-8432) were all from Santa Cruz Biotechnology, Inc. (Dallas, TX, USA). The immunohistochemistry (IHC) kit was purchased from Fuzhou Maixin Biotechnology Co., Ltd. (Fuzhou, China). Culture medium Dulbecco's modified Eagle's medium (DMEM), fetal bovine serum (FBS) and trypsin were purchased from Gibco; Thermo Fisher Scientific, Inc. (Waltham, MA, USA). Primers for qPCR and siRNA for CCDC34 were synthesized by Shanghai Sangon Biotech, Co., Ltd. (Shanghai, China). Lipofectamine 2000 reagent was obtained from Invitrogen; Thermo Fisher Scientific, Inc. Apoptosis detection kits containing Annexin V-FITC and PI were purchased from Wuhan Boster Biological Technology, Ltd., (Wuhan, China). Caspase-3 and -8 Activity Assay kits were obtained from EMD Millipore (Billerica, MA, USA).

IHC analysis. Sections were fixed with $4 \%$ neutral buffered formalin for $24 \mathrm{~h}$, and cut from each paraffin tissue block of CRC with $4 \mu \mathrm{m}$ thickness, and antigen retrieval was performed according to following steps: Sections were immersed in citrate buffer $(\mathrm{pH}=6.0)$, and the pressure cooker antigen retrieval method was utilized for $4 \mathrm{~min}$. Sections were removed, the buffer was allowed to come to room temperature and the sections were rinsed 3 times $(5 \mathrm{~min}$ each time). They were subjected to the IHC procedure following the manufacturer's protocol and the results were examined by a professional pathologist. The number and the percentage of positive cells were calculated in 100 cells from randomly chosen 5 fields in each section using a TE2000-U microscope (x400; Nikon Corporation, Tokyo, Japan). The dilutions of antibodies were as following: CCDC34 (1:200), Bcl-2 (1:400), survivin (1:400), E-cadherin (1:400), N-cadherin (1:250), MMP-9 (1:400). The duration of each incubation step was performed at $37^{\circ} \mathrm{C}$ for $3 \mathrm{~h}$ according to the relevant manufacturer's instructions. The cells with yellow or brown particles in the cytoplasm were considered to be positive for CCDC34, Bcl-2, survivin, E-cadherin, N-cadherin and MMP-9. The scoring was performed with the percentage of positive cells $(0,0-25 \% ; 1,25-50 \% ; 2,51-75 \% ; 3,76-100 \%)$ and intensity of staining ( 0 , no staining; 1 , pale yellow; 2 , yellow; 3 , brown). The percentage of positive cells and intensity of staining were added up to produce the result for each case: 0 , Negative staining (-), 1-2 as mild staining (+), 3-4, moderate staining $(++), 5-6$, intense staining $(+++)$. A result of $(-)$ was recorded as negative and results of $(+),(++)$, and $(+++)$ were recorded as positive.

Cell culture. HCT8, HCT116, SW620, SW480, LS-174T, HT29 human colon cancer cell lines which were cultured in DMEM containing $10 \% \mathrm{FBS}$ and incubated at $37^{\circ} \mathrm{C}$ supplemented with $5 \% \mathrm{CO}_{2}$ was passaged every 2-3 days. The cells at logarithmic growth phase were used for the subsequent experiments. This procedure was repeated three times.

CCDC34-siRNA transfection and groups. The synthesized CCDC34-siRNA sequence was 5'-GCCUGAGAGGAAUGG AGUUTT-3' and negative control (NS) siRNA sequence 5'-UUCUCCGAACGUGUCACGUTT-3'. SW620 cells were transfected with various concentrations of CCDC34-siRNA or NS-siRNA using Lipofectamine 2000 and used for subsequent experiments after $48 \mathrm{~h}$. The cells were assigned into CCDC34-siRNA group, NS-siRNA group and blank control group (treated only with Lipofectamine 2000 reagent).

MTT assay. Tumor single-cell suspensions were prepared and seeded in 96 -well plate $\left(10^{5}\right.$ cells/well). MTT $(20 \mu \mathrm{l})$ solution $(5 \mathrm{mg} / \mathrm{ml})$ was added to each well $4 \mathrm{~h}$ prior the end of the experiment and then following a $4 \mathrm{~h}$ incubation at room temperature, the culture medium was removed and $150 \mu \mathrm{l}$ DMSO was added to each well. The absorbance values were determined following shaking at room temperature for $15 \mathrm{~min}$ at $490 \mathrm{~nm}$ using a microplate reader.

Cell apoptosis assay. The cells of all groups transfected for $48 \mathrm{~h}$ were collected by trypsinization after rinsed with PBS and the cell density was adjusted to $5 \times 10^{5}$ cells $/ \mathrm{ml}$. Then, $500 \mu \mathrm{l}$ binding buffer was added to suspend cells and $10 \mu \mathrm{l}$ Annexin V-FITC or PI was added and mixed respectively. The cells were counted by FACS flow cytometry after incubation in dark for $15 \mathrm{~min}$ and subjected to calculate percentage of apoptotic cells.

Cell invasion ability assay. SW620 cells were seeded in 24-well plates with $10^{5}$ cells/well and treated as the different groups, which were transfected with CCDC34-siRNA or NS-siRNA. Transwell chambers were coated with $100 \mu \mathrm{l}$ Matrigel was treated with ultraviolet radiation. SW620 cells from each group were seeded in $200 \mu \mathrm{l}$ in the upper chamber with serum free DMEM, and DMEM medium containing 20\% FBS was added to the lower chamber. After $24 \mathrm{~h}$, Matrigel glue and extra SW620 cells in the upper chamber were wiped with cotton swabs. Methanol was utilized to fix the membranes for $10 \mathrm{~min}$. The cells penetrating to the lower membrane were counted following crystal violet staining. Each experiment was repeated 3 times. 
Table I. Primer sequences for reverse transcription-quantitative polymerase chain reaction.

\begin{tabular}{lll}
\hline Gene & \multicolumn{1}{c}{ Forward $\left(5^{\prime}-3^{\prime}\right)$} & \multicolumn{1}{c}{ Reverse $\left(5^{\prime}-3^{\prime}\right)$} \\
\hline CCDC34 & ACAGAAACAGGTGCGCTTACC & CAGCCGGTCACGTTCTTCTTT \\
Bcl-2 & TGTGTGGAGAGCGTCAACC & TGGATCCAGGTGTGCAGGT \\
Survivin & GCCAGATTTGAATCGCGGGA & GCAGTGGATGAAGCCAGCCT \\
E-cadherin & CACTCGTCGCTGGATCTGTCA & CACAGCCTACTGCATGGCTCA \\
N-cadherin & GAGATCCTACTGGACGGTTCG & TCTTGGCGAATGATCTTAGGA \\
MMP-9 & AGAACCAATCTCACCGACAGG & CGACTCTCCACGCATCTCT \\
GAPDH & GACCCCTTCATTGACCTCAAC & CGCTCCTGGAAGATGGTGAT
\end{tabular}

CCDC34, coiled-coil domain containing 34; Bc12, B cell leukemia/lymphoma 2; MMP-9, matrix metallopeptidase-9.

$R T-q P C R$. The cells were collected $48 \mathrm{~h}$ after transfection and total RNA was isolated using the TRIzol reagent (Invitrogen; Thermo Fisher Scientific, Inc.) according to the manufacturer's protocol. RNA $(2 \mu \mathrm{g})$ was reverse transcribed to synthesize first-strand cDNA according to the instruction of Reverse Transcription System kit (Promega Corporation. Madison, WI, USA) according to following steps: $25^{\circ} \mathrm{C}$ for $5 \mathrm{~min}, 42^{\circ} \mathrm{C}$ for $60 \mathrm{~min}, 70^{\circ} \mathrm{C}$ for $15 \mathrm{~min}$. cDNA templates $(2 \mu \mathrm{g})$ were amplified by qPCR using SYBR Green PCR kit (Promega Corporation) to establish a $25 \mu \mathrm{l}$ reaction system on an RT-qPCR machine. PCR reaction started with 1 cycle of $95^{\circ} \mathrm{C}$ for $5 \mathrm{~min}$, followed by 45 cycles of $2 \mathrm{steps}$ as $95^{\circ} \mathrm{C}$ for $30 \mathrm{sec}$, $72^{\circ} \mathrm{C}$ for $30 \mathrm{sec}$ and $72^{\circ} \mathrm{C}$ for $5 \mathrm{~min}$. The quantification cycle (Cq) (16) was obtained from the reaction curve and the expression of targeted genes was normalized to the housekeeping gene GAPDH. The primers used are listed in Table I.

Western blotting. Cell protein was extracted with cell lysis buffer (Sigma-Aldrich; Merck KGaA) 48 h after transfection and protein concentrations were determined by Bradford assay. Protein $(40 \mu \mathrm{g})$ was loaded and separated on a $12 \%$ SDS-PAGE gel and transferred to a polyvinylidene fluoride membrane. Membranes were blocked with 5\% fetal bovine serum (Thermo Fisher Scientific, Inc.) in Tris-buffered saline with $0.05 \%$ Tween-20 (TBST) for $1 \mathrm{~h}$ at room temperature and incubated with primary antibodies of interest overnight at $4^{\circ} \mathrm{C}$. The dilutions of antibodies were as following: CCDC34 (1:800), Bcl-2 (1:1,000), survivin (1:400), E-cadherin (1:800), N-cadherin (1:1,000), MMP-9 (1:400). After being washed with TBST 3 times, membranes were incubated with IgG secondary antibody (1:1,000, sc-2007; Santa Cruz Biotechnology, Inc.) for $1 \mathrm{~h}$ at room temperature and subjected to color development. The absorbance of target bands was detected with an Odyssey Infrared Imaging System (9120; Li-COR Biosciences, Lincoln, NE, USA) to determine the relative expression intensity of the proteins.

Caspase-3 and - 8 activity assays. The activity of caspase-3 and -8 was detected by spectrophotometry. Cells were collected, lysed for 20 min using the cold lysis buffer, and centrifuged for $10 \mathrm{~min}$ at $12,500 \mathrm{x} \mathrm{g}$. The supernatant was transferred to test the protein concentration. The analysis was performed according to the manufacturer's protocol of the activity detection kits. The absorbance values at the wavelength of $405 \mathrm{~nm}$ were obtained from a microplate reader. The caspase activity was presented as caspase enzyme units in per unit cell protein.

Statistical analysis. Statistical analyses were performed with SPSS software version 19.0 (IBM Corp., Armonk, NY, USA). Chi-squared test, Mann-Whitney rank sum test, Spearman correlation, one-way analysis of variance and Dunnett's test were used for data analysis. $\mathrm{P}<0.05$ was considered to indicate a statistically significant difference.

\section{Results}

CCDC34 protein expression in CRC tissues and adjacent normal mucosa. The IHC results illustrated the CCDC34-positive rate in the $85 \mathrm{CRC}$ tissues was $74.12 \%$ $(63 / 85)$ and $28.33 \%(17 / 60)$ in paracancerous tissues. As presented in Fig. 1, the expression of CCDC34 was increased in CRC tissues compared with adjacent tissues $\left(\chi^{2}=29.810\right.$, $\mathrm{P}<0.001)$.

Association between CCDC34 protein expression and CRC clinical pathology parameters. Findings are presented in Table II and revealed that the protein expression of CCDC34 was related to invasion depth of the tumor, differentiation and metastasis in the lymph node. CCDC34-positive CRC tissues were characterized with deeper infiltrating of the tumor and higher positive rate of lymphatic metastasis $(\mathrm{P}<0.05)$. No significant association was identified between CCDC34 protein expression and the remaining biological characteristics $(\mathrm{P}>0.05)$.

Alteration of CCDC34 protein expression in SW620 cells post CCDC34-siRNA treatment. The protein expression levels of CCDC34 in SW620 cells transfected with CCDC34-siRNA for $48 \mathrm{~h}$ was detected with western blotting. As demonstrated in Fig. 2, CCDC34 protein expression in the CCDC34-siRNA transfected group was significantly lower than the negative control and blank control groups $(\mathrm{P}<0.05)$, whereas there was no obvious difference between the NS-siRNA group and the blank control groups $(\mathrm{P}>0.05)$.

Metabolic activity of SW620 cells following CCDC34-siRNA treatment. In Fig. 3, metabolic activity of SW620 cells transfected 
Table II. Relationship between coiled-coil domain containing 34 protein expression and clinicopathological characteristics of patients with colorectal cancer.

\begin{tabular}{|c|c|c|c|c|c|}
\hline Clinicopathological parameters & Positive (63) & Negative (22) & Total & $\chi^{2}$ & $\mathrm{P}$ \\
\hline \multicolumn{6}{|l|}{ Sex } \\
\hline Male & 45 & 14 & 59 & \multirow[t]{2}{*}{0.466} & \multirow[t]{2}{*}{0.495} \\
\hline Female & 18 & 8 & 26 & & \\
\hline \multicolumn{6}{|l|}{ Age (years) } \\
\hline$\geq 60$ & 18 & 9 & 27 & \multirow[t]{2}{*}{1.145} & \multirow[t]{2}{*}{0.285} \\
\hline$<60$ & 45 & 13 & 58 & & \\
\hline \multicolumn{6}{|l|}{ Tumor differentiation } \\
\hline Well-differentiated & 45 & 17 & 62 & \multirow[t]{2}{*}{0.282} & \multirow[t]{2}{*}{0.595} \\
\hline Poorly differentiated & 18 & 5 & 23 & & \\
\hline \multicolumn{6}{|l|}{ Depth of invasion } \\
\hline Serosal infiltration & 49 & 12 & 61 & \multirow[t]{2}{*}{4.343} & \multirow[t]{2}{*}{0.037} \\
\hline No serosal infiltration & 14 & 10 & 24 & & \\
\hline \multicolumn{6}{|l|}{ Lymphatic metastasis } \\
\hline Positive & 51 & 11 & 62 & \multirow[t]{2}{*}{7.915} & \multirow[t]{2}{*}{0.005} \\
\hline Negative & 12 & 11 & 23 & & \\
\hline \multicolumn{6}{|l|}{ TNM stages } \\
\hline I & 5 & 4 & 9 & \multirow[t]{4}{*}{2.012} & \multirow[t]{4}{*}{0.570} \\
\hline II & 10 & 4 & 14 & & \\
\hline III & 43 & 12 & 55 & & \\
\hline IV & 5 & 2 & 7 & & \\
\hline \multicolumn{6}{|l|}{ Distant metastasis } \\
\hline Positive & 5 & 2 & 7 & \multirow[t]{2}{*}{0.029} & \multirow[t]{2}{*}{0.865} \\
\hline Negative & 58 & 20 & 78 & & \\
\hline
\end{tabular}

TNM, tumor-node-metastasis.

A

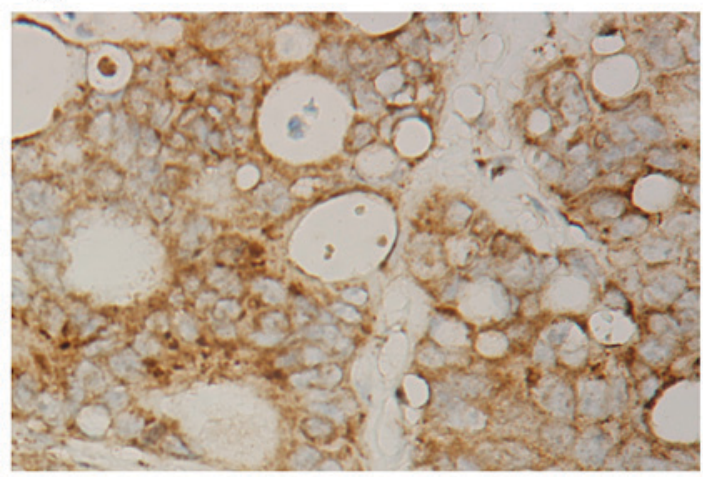

B

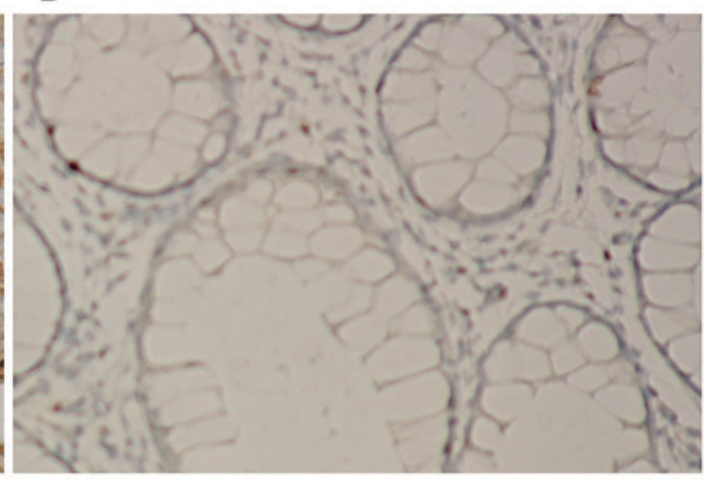

Figure 1. Expression of CCDC34 protein in CRC and adjacent normal mucosa tissues. A total of 85 paraffin tissues from patients with CRC were collected to determine CCDC34 protein expression using immunohistochemistry. Positive staining for CCDC34 protein was located in cell membrane and/or cytoplasm. Expression level of CCDC34 protein in (A) CRC tissues and (B) adjacent normal mucosa tissues. CCDC34, coiled-coil domain containing 34; CRC, colorectal cancer.

with CCDC34-siRNA for $48 \mathrm{~h}$ was $0.232 \pm 0.031$, and was significantly lower compared with the NS-siRNA group (0.283 \pm 0.029$)$ and the blank group $(0.306 \pm 0.041 ; \mathrm{P}<0.05)$, whereas there was no difference observed between con-siRNA group and the blank control group $(\mathrm{P}>0.05)$.
Apoptosis rate of SW620 cells post CCDC34-siRNA treatment. In Fig. 4, the apoptotic rate of SW620 cells transfected with CCDC34-siRNA was $28.62 \pm 4.57 \%$ compared with $12.65 \pm 3.05 \%$ in the NS-siRNA group and $11.26 \pm 2.26 \%$ in the blank group. This indicated that the 

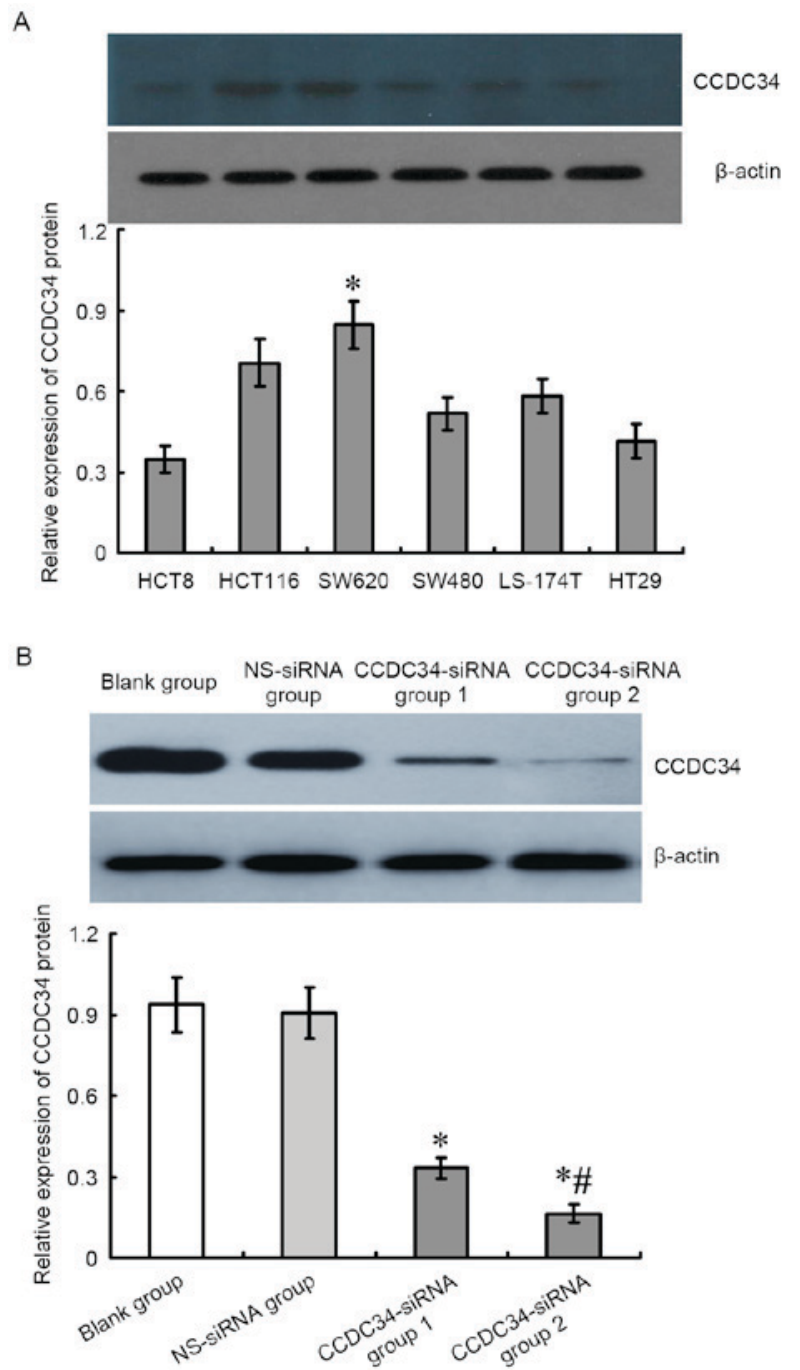

Figure 2. Different expression levels of CCDC34 protein in CRC cell lines and inhibitory effect of CCDC34-siRNA on CCDC34 expression in SW620 cells. (A) From the 6 CRC cell lines, the highest CCDC34 protein expression was detected in the SW620 cells; therefore, the SW620 cells were used for subsequent experiments. "P $<0.05$ vs. HCT8, HCT116, SW480, LS-174T, HT29 cells. (B) CCDC34-siRNA was transfected into SW620 cells, CCDC34 expression level was significantly downregulated following CCDC34-siRNA transfection. Group 1, $20 \mu \mathrm{mol} / 1$; Group 2, $80 \mu \mathrm{mol} / 1$; ${ }^{*} \mathrm{P}<0.05$ vs. blank or NS-siRNA groups, ${ }^{\#} \mathrm{P}<0.05$ vs. CCDC34-siRNA group 1. CCDC34, coiled-coil domain containing 34; NS, negative control; siRNA, small interfering RNA; CRC, colorectal cancer.

apoptotic rate of the CCDC34-siRNA group was evidently elevated when compared with the two other groups $(\mathrm{P}<0.01)$.

Cell invasion ability of SW620 cells following CCDC34-siRNA treatment. As presented in Fig. 5, Transwell assay results highlighted the lower number of SW620 cells crossing the Transwell chamber membrane in the CCDC34-siRNA group (50.17 \pm 6.15$)$ compared with the NS-siRNA group $(83.50 \pm 6.47)$ and the blank group $(85.67 \pm 5.05 ; \mathrm{P}<0.05)$, whereas there was no obvious difference between the NS-siRNA and blank groups $(\mathrm{P}>0.05)$.

Alteration of the expression of apoptosis-associated BCl-2 and caspase-3, -8 activity in SW620 cells following CCDC34-siRNA treatment. In Fig. 6A-C, mRNA and protein

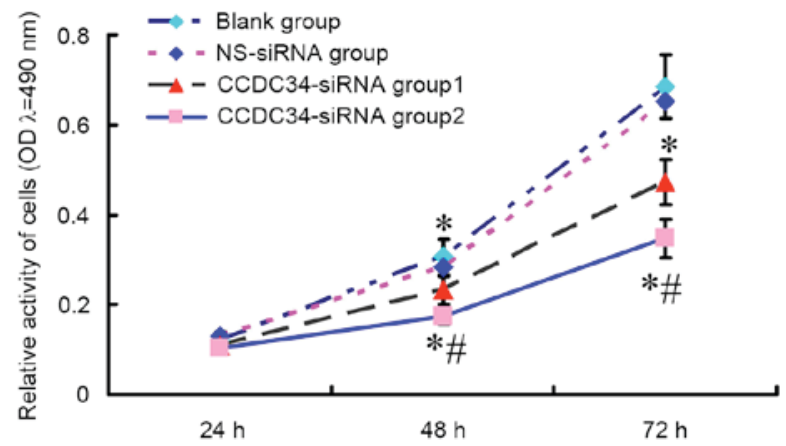

Figure 3. Effect of CCDC34-siRNA on the metabolic cell activity of SW620 cells. The metabolic activity of SW620 cells varied with different concentrations and time following CCDC34-siRNA transfection. Compared with NS-siRNA group and blank group, activity of SW620 cells in CCDC34-siRNA group decreased significantly in the time-dependent manner. Group 1 , $20 \mu \mathrm{mol} / 1$; Group 2, $80 \mu \mathrm{mol} / 1$; "P $<0.05$ vs. blank or NS-siRNA groups, ${ }^{*} \mathrm{P}<0.05$ vs. CCDC34-siRNA group 1. CCDC34, coiled-coil domain containing 34; NS, negative control; siRNA, small interfering RNA; OD, optical density.

expression levels of Bcl-2 and survivin were significantly decreased in cells of CCDC34-siRNA group when compared with the NS-siRNA and blank groups $(\mathrm{P}<0.05)$. No obvious difference was identified between the NS-siRNA group and the blank group $(\mathrm{P}>0.05)$. Additionally, the activity of caspase- 3 and -8 in cells of CCDC34-siRNA group was higher compared with the control groups $(\mathrm{P}<0.05)$, whereas there was no obvious difference between the NS-siRNA and blank groups $(\mathrm{P}>0.05$; Fig. 6D).

Alteration of the expression of invasion-associated genes in SW620 cells following CCDC34-siRNA treatment. As presented in Fig. 7, western blotting and RT-qPCR revealed mRNA and protein expression of E-cadherin was significantly increased in cells of the CCDC34-siRNA group compared with the control groups $(\mathrm{P}<0.05)$, whereas that of $\mathrm{N}$-cadherin and MMP-9 were significantly reduced $(\mathrm{P}<0.05)$. No obvious difference between the NS-siRNA group and the blank group was identified $(\mathrm{P}>0.05)$.

\section{Discussion}

CRC is one of the most common cancers globally (17). Although the treatments have improved in terms of surgical technique (18), radiotherapy (19), chemotherapeutics and targeted drugs for patients CRC $(20,21)$, the overall therapeutic efficacy is unsatisfactory with a high mortality rate, which leads to suffering patients and also a considerable burden to society (22). Therefore, investigating the pathogenesis and developing novel therapies have been hotspots in CRC research. Recurrence and metastasis are primary causes of death for CRC patients; therefore, methods blocking this process may potentially improve CRC treatment. Previous studies have reported that CRC cells which have high anti-apoptotic and invasion abilities are prone to rapid progression and metastasis $(23,24)$. The anti-apoptosis and invasion of CRC cells may be due to the combined effects of multiple genes, and considering that, it is important to identify the key genes relevant to this process. Some genes have been previously identified associated with 

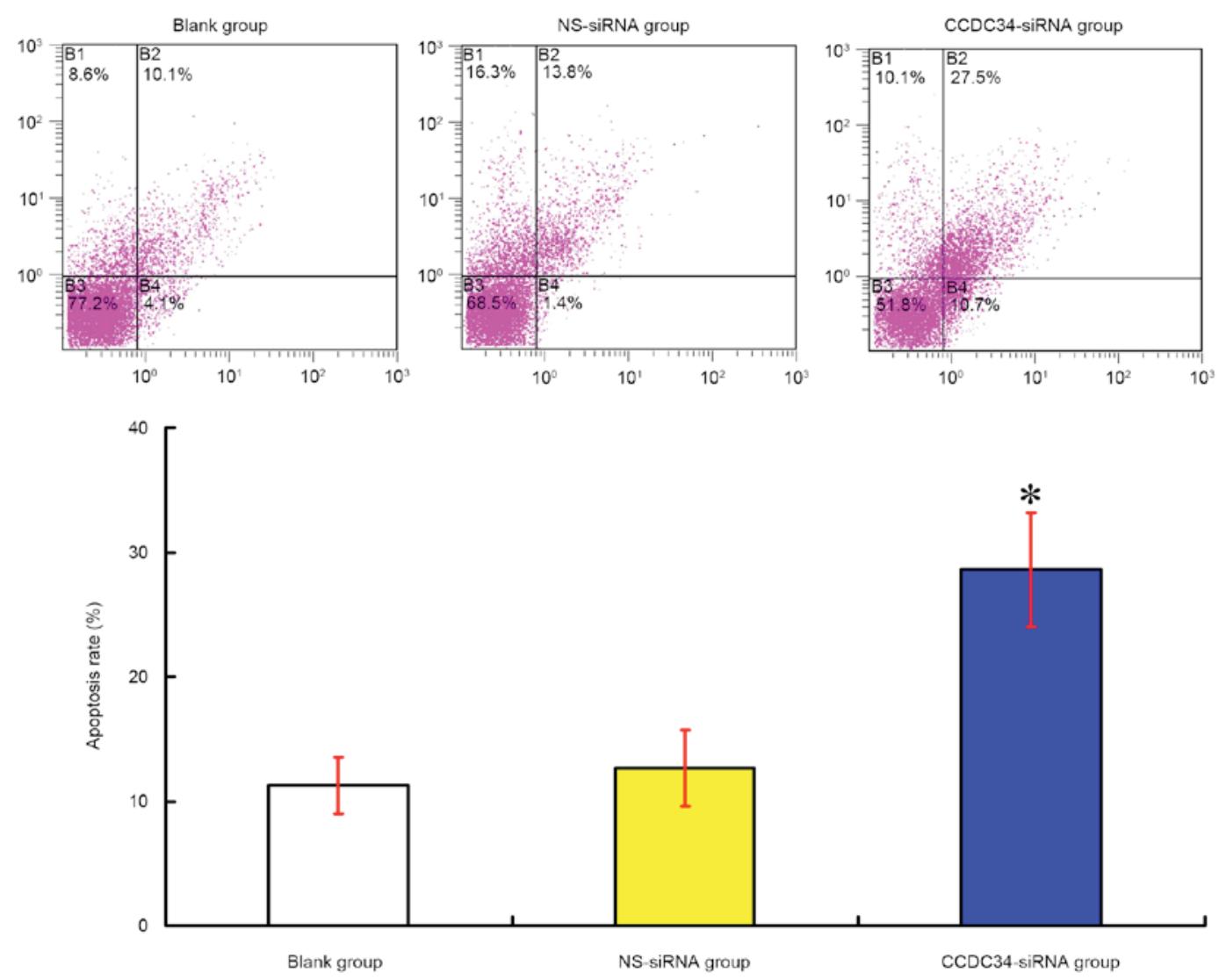

Figure 4. Effects of CCDC34-siRNA on apoptosis of SW620 cells. SW620 cells were transfected with CCDC34-siRNA and were then subjected to flow cytometry to detect the apoptotic rate and the apoptotic rate of SW620 cells was increased after CCDC34-siRNA transfection. "P<0.05 vs. blank or NS-siRNA groups. CCDC34, coiled-coil domain containing 34; NS, negative control; siRNA, small interfering RNA.

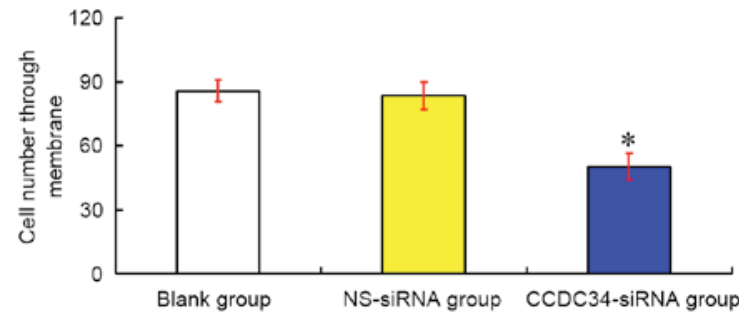

Figure 5. Effects of CCDC34-siRNA on invasion of SW620 cells. SW620 cells were transfected with CCDC34-siRNA and then were subjected to Transwell assay to detect cell invasion activity. Invasion of SW620 cells was decreased after CCDC34-siRNA transfection. "P<0.05 vs. blank or NS-siRNA groups. CCDC34, coiled-coil domain containing 34; NS, negative control; siRNA, small interfering RNA.

anti-apoptosis and invasion of CRC cells; however, specific mechanisms remain to be elucidated. CCDC, a protein with a coiled-coil structure, has the functions of metabolism regulation, cell membrane channel and molecular chaperone $(25,26)$. The association between some members of the CCDC family and cancers has been investigates previously. Gong et al (15) revealed that abnormal high expression of CCDC34, a member of CCDC family, was detected in bladder cancer cells, and suppression of CCDC34 contributed to the reduced proliferation and invasion and increased apoptosis of cancer cells. The present study observed high expression of CCDC34 in CRC tissues, particularly in tissues with deep tumor invasion and lymphatic metastasis. This infers that CCDC34 contributed to
CRC progression and metastasis, and detection of CCDC34 in CRC tissues may provide information to evaluate patients' condition. Anti-apoptosis, invasion and metastasis of cancer cells have important roles in progression of CRC. As CRC cells have anti-apoptotic ability, previous studies regarding CRC treatment are focused on how to suppress anti-apoptotic ability of CRC cells $(27,28)$. In addition, considering CRC cells have strong invasive and metastatic ability, suppression of these abilities may control tumor development $(29,30)$. In the in vitro experiments in the present study, reduced cell metabolic activity, increased apoptotic rate and decreased invasion were observed following the suppression of the expression of CCDC34 in the SW620 cell line, which may indicate that CCDC34 may have the ability to regulate cell apoptosis and invasion. In order to determine the role of CCDC34 in apoptosis and invasion of CRC cells, the expression levels of apoptosis and invasion-associated genes in CRC cells were detected following the suppression of CCDC34 expression and the role of CCDC34 in CRC was investigated.

$\mathrm{Bcl}-2$ is an important gene that regulates apoptosis through the mitochondrial pathway and it is able to suppress cell apoptosis in various ways $(31,32)$. Survivin, a member of inhibitor of apoptosis proteins family, is able to suppress apoptosis by suppressing caspase- 3 and -8 activity which are apoptosis promoting molecules $(33,34)$. In the current study, reduced expression of Bcl-2 and survivin was detected in the SW620 cell line following CCDC34 inhibition, whereas the activity of caspase-3 and -8 was increased. This suggested that CCDC34 

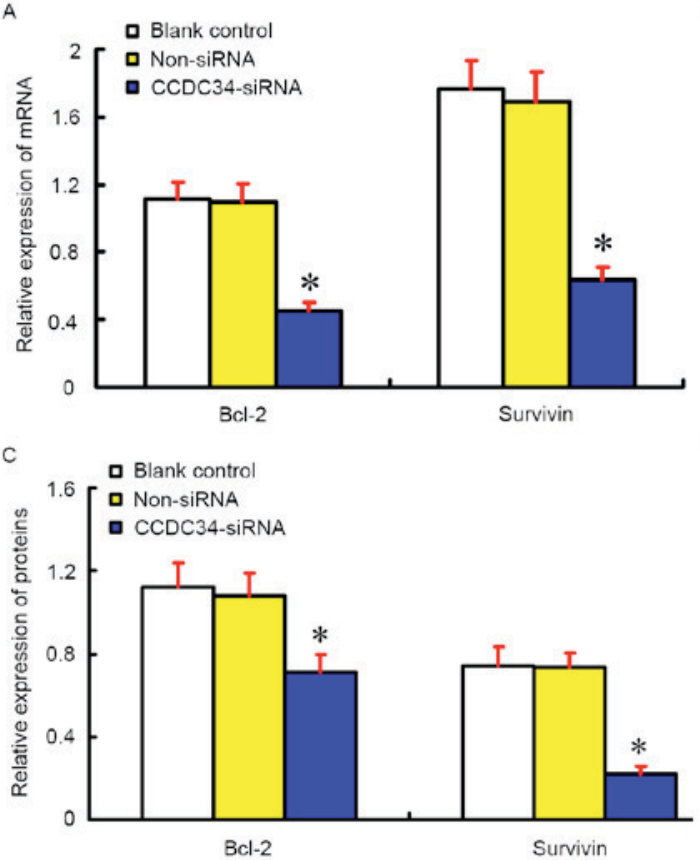
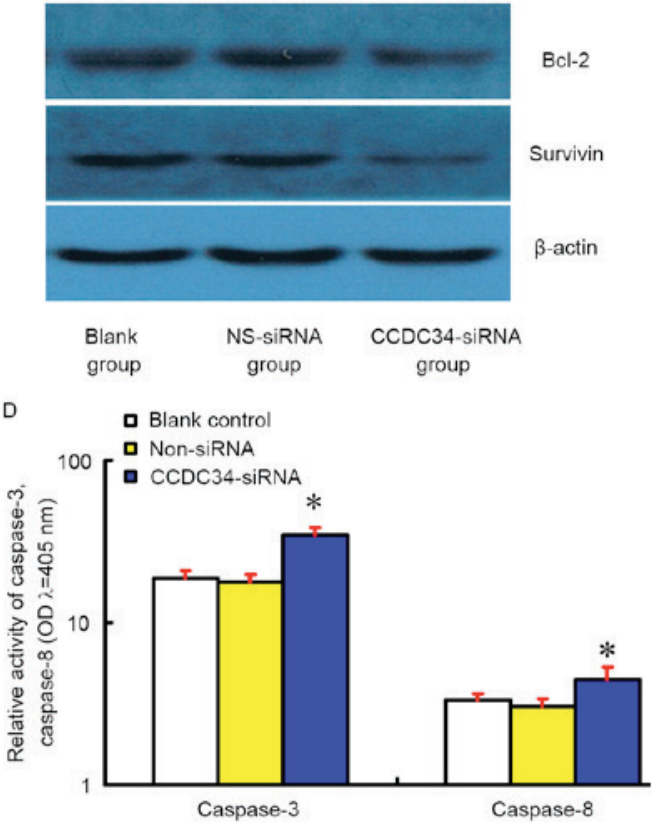

Figure 6. Effect of CCDC34-siRNA on the mRNA expression levels of Bcl-2, survivin, and caspase-3 and 8 activity in SW620 cells. SW620 cells were transfected with CCDC34-siRNA and were then subjected to (A) reverse transcription-quantitative polymerase chain reaction and (B and C) western blotting, to detect the mRNA and protein expression levels of Bcl-2 and survivin, respectively. (D) The activity of caspase-3 and - 8 increased significantly after CCDC34-siRNA transfection. ${ }^{*} \mathrm{P}<0.05$ vs. blank or NS-siRNA groups. CCDC34, coiled-coil domain containing 34; NS, negative control; siRNA, small interfering RNA; Bcl-2, B cell leukemia/lymphoma 2.

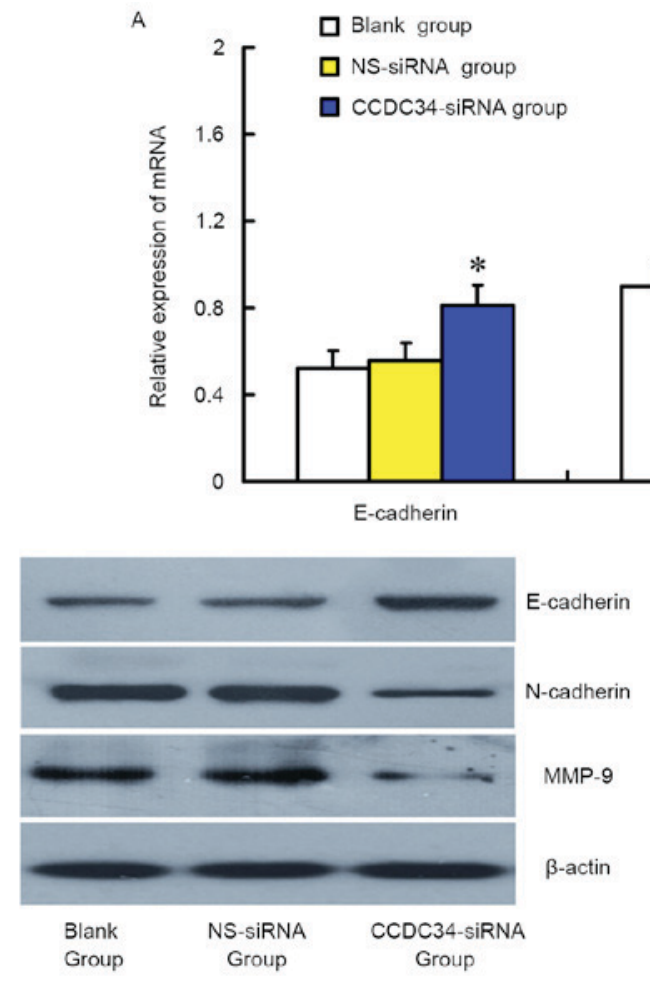

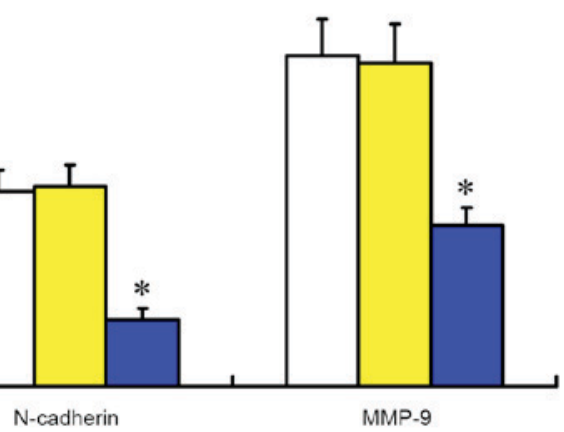

c

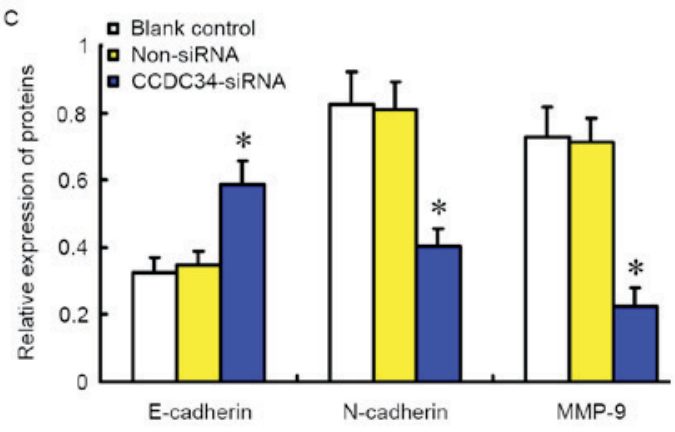

Figure 7. Effect of CCDC34-siRNA on the expression levels of E-cadherin, N-cadherin and MMP-9 in SW620 cells. SW620 cells were transfected with CCDC34-siRNA and were then subjected to (A) reverse transcription-quantitative polymerase chain reaction and (B and C) western blotting. E-cadherin expression was increased, whereas N-cadherin and MMP-9 decreased in SW620 cells. "P<0.05 vs. blank or NS-siRNA groups. CCDC34, coiled-coil domain containing 34; NS, negative control; siRNA, small interfering RNA; MMP-9, matrix metallopeptidase-9.

increased apoptosis resistance by activating $\mathrm{Bcl}-2$ and survivin and suppressing caspase- 3 and caspase- 8 .
Epithelial-mesenchymal transition (EMT) has been identified to participate in cancer invasion and metastasis (35). 
In the current study, the changes of EMT-associated genes in SW620 cell line following suppression of CCDC34 was also detected. E-cadherin, a transmembrane glycoprotein in epithelial cells, is essential for cell junction and integrity of structure $(36,37)$. Previous studies have revealed that the downregulation of E-cadherin expression may trigger the invasion and expansion of basement membrane, which may lead to tumor invasion and metastasis $(38,39)$. $\mathrm{N}$-cadherin is one of the important mesenchymal markers and its upregulated expression is the hallmark of EMT, as well as an indicator of tumor invasion and metastasis $(40,41)$. MMP-9, one of the important members of the MMPs family is involved in the degradation of extracellular matrix and contribution to metastasis in tumors $(7,8,42,43)$ and regulated by E-cadherin (44). The present study determined that E-cadherin expression was significantly increased following the inhibition of the endogenous CCDC34 expression by RNA interference, whereas expression of N-cadherin and MMP-9 was decreased. This indicates that CCDC34 is involved in CRC EMT, which may lead to cancer invasion and metastasis by suppressing E-cadherin and promoting N-cadherin and MMP-9. However, the corresponding molecular mechanisms should be further clarified by future studies.

In conclusion, the present study demonstrated increased expression of CCDC34 protein in CRC tissues was associated with reduced apoptosis and increased metastasis in CRC cell line. CCDC34 may promote anti-apoptosis and invasion by regulating $\mathrm{Bcl}-2$, survivin, E-cadherin, $\mathrm{N}$-cadherin and MMP-9. However, the sample size in the present study was limited and the in vitro experiments are insufficient. Despite the limitations, it may be concluded that CCDC34 had an important role in CRC invasion and metastasis. Further investigation of the functions of CCDC34 may be beneficial to CRC evaluation and CCDC34 may also be regarded as the target gene for controlling CRC progression and metastasis.

\section{References}

1. Hashim D, Boffetta P, La Vecchia C, Rota M, Bertuccio P, Malvezzi $M$ and Negri E: The global decrease in cancer mortality: Trends and disparities. Ann Oncol 27: 926-933, 2016.

2. Favoriti P, Carbone G, Greco M, Pirozzi F, Pirozzi RE and Corcione F: Worldwide burden of colorectal cancer: A review. Updates Surg 68: 7-11, 2016.

3. Schreuders EH, Ruco A, Rabeneck L, Schoen RE, Sung JJ, Young GP and Kuipers EJ: Colorectal cancer screening: A global overview of existing programmes. Gut 64: 1637-1649, 2015.

4. Simpkins SJ, Pinto-Sanchez MI, Moayyedi P, Bercik P, Morgan DG, Bolino C and Ford AC: Poor predictive value of lower gastrointestinal alarm features in the diagnosis of colorectal cancer in 1981 patients in secondary care. Aliment Pharmacol Ther 45: 91-99, 2017.

5. Tokodai K, Narimatsu H, Nishida A, Takaya K, Hara Y, Kawagishi N, Hashizume E and Ohuchi N: Risk factors for recurrence in stage II/III colorectal cancer patients treated with curative surgery: The impact of postoperative tumor markers and an infiltrative growth pattern. J Surg Oncol 114: 368-374, 2016.

6. Vatandoust S, Price TJ and Karapetis CS: Colorectal cancer: Metastases to a single organ. World J Gastroenterol 21: 11767-11776, 2015.

7. Chen GQ, Tang CF, Shi XK, Lin CY, Fatima S, Pan XH, Yang DJ, Zhang G, Lu AP, Lin SH and Bian ZX: Halofuginone inhibits colorectal cancer growth through suppression of Akt/mTORC1 signaling and glucose metabolism. Oncotarget 6: 24148-24162, 2015 .
8. He G, Feng C, Vinothkumar R, Chen W, Dai X, Chen X, Ye Q, Qiu C, Zhou H, Wang Y, et al: Curcumin analog EF24 induces apoptosis via ROS-dependent mitochondrial dysfunction in human colorectal cancer cells. Cancer Chemother Pharmacol 78: 1151-1161, 2016.

9. Sathyanarayanan A, Chandrasekaran KS and Karunagaran D: microRNA-146a inhibits proliferation, migration and invasion of human cervical and colorectal cancer cells. Biochem Biophys Res Commun 480: 528-533, 2016.

10. Modjtahedi N, Tokatlidis K, Dessen P and Kroemer G: Mitochondrial proteins containing Coiled-Coil-Helix-Coiled-Co il-Helix $(\mathrm{CHCH})$ domains in health and disease. Trends Biochem Sci 41: 245-260, 2016

11. Yin DT, Xu J, Lei M, Li H, Wang Y, Liu Z, Zhou Y and Xing M: Characterization of the novel tumor-suppressor gene CCDC67 in papillary thyroid carcinoma. Oncotarget 7: 5830-5841, 2016.

12. Morra F, Luise C, Visconti R, Staibano S, Merolla F, Ilardi G, Guggino G, Paladino S, Sarnataro D, Franco R, et al: New therapeutic perspectives in CCDC6 deficient lung cancer cells. Int J Cancer 136: 2146-2157, 2015.

13. Zhong J, Zhao M, Luo Q, Ma Y, Liu J, Wang J, Yang M, Yuan X, Sang J and Huang C: CCDC134 is down-regulated in gastric cancer and its silencing promotes cell migration and invasion of GES-1 and AGS cells via the MAPK pathway. Mol Cell Biochem 372: 1-8, 2013.

14. Park SJ, Jang HR, Kim M, Kim JH, Kwon OH, Park JL, Noh SM, Song KS, Kim SY, Kim YH and Kim YS: Epigenetic alteration of CCDC67 and its tumor suppressor function in gastric cancer. Carcinogenesis 33: 1494-1501, 2012.

15. Gong Y, Qiu W, Ning X, Yang X, Liu L, Wang Z, Lin J, Li X and Guo Y: CCDC34 is up-regulated in bladder cancer and regulates bladder cancer cell proliferation, apoptosis and migration. Oncotarget 6: 25856-25867, 2015.

16. Livak KJ and Schmittgen TD: Analysis of relative gene expression data using real-time quantitative PCR and the 2(-Delta Delta C(T)) method. Methods 25: 402-408, 2001.

17. Bode AM, Dong Z and Wang H: Cancer prevention and control: Alarming challenges in China. Natl Sci Rev 3: 117-127, 2016.

18. Ratti F, Catena M, Di Palo S, Staudacher C and Aldrighetti L: Impact of totally laparoscopic combined management of colorectal cancer with synchronous hepatic metastases on severity of complications: A propensity-score-based analysis. Surg Endosc 30: 4934-4945, 2016.

19. Ahmed I, Howard M, Rehman Z, Ofar F, Marley P, O'Doherty E and Martin MJ: A comparison of overall and disease-specific survivals following adjuvant radiotherapy with neo-adjuvant radiotherapy for rectal cancer. J Clin Oncol 27 (15 suppl): e15008, 2009.

20. Bartoş A, Bartoş D, Szabo B, Breazu C, Opincariu I, Mironiuc A and Iancu C: Recent achievements in colorectal cancer diagnostic and therapy by the use of nanoparticles. Drug Metab Rev 48: 27-46, 2016.

21. Verdaguer H, Tabernero $\mathrm{J}$ and Macarulla T: Ramucirumab in metastatic colorectal cancer: Evidence to date and place in therapy. Ther Adv Med Oncol 8: 230-242, 2016.

22. Chen W, Zheng R, Zeng H and Zhang S: The updated incidences and mortalities of major cancers in China, 2011. Chin J Cancer 34: 53-507, 2015

23. Kawakami H, Huang S, Pal K, Dutta SK, Mukhopadhyay D and Sinicrope FA: Mutant BRAF upregulates MCL-1 to confer apoptosis resistance that is reversed by MCL- 1 antagonism and cobimetinib in colorectal cancer. Mol Cancer Ther 15: 3015-3027, 2016.

24. Feng Y, Feng L, Yu D, Zou J and Huang Z: srGAP1 mediates the migration inhibition effect of Slit2-Robol in colorectal cancer. J Exp Clin Cancer Res 35: 191, 2016.

25. Truebestein L and Leonard TA: Coiled-coils: The long and short of it. Bioessays 38: 903-916, 2016.

26. Peralta S, Clemente P, Sánchez-Martínez A, Calleja M, Hernández-Sierra R, Matsushima Y, Adán C, Ugalde C, Fernández-Moreno, MÁ, Kaguni LS and Garesse R: Coiled coil domain-containing protein 56 (CCDC56) is a novel mitochondrial protein essential for cytochrome c oxidase function. J Biol Chem 287: 24174-24185, 2012.

27. Fan XJ, Wang Y, Wang L and Zhu M: Salidroside induces apoptosis and autophagy in human colorectal cancer cells through inhibition of PI3K/Akt/mTOR pathway. Oncol Rep 36: 3559-3567, 2016.

28. Jayathilake AG, Senior PV and Su XQ: Krill oil extract suppresses cell growth and induces apoptosis of human colorectal cancer cells. BMC Complement Altern Med 16: 328, 2016. 
29. Chen Z, Han S, Huang W, Wu J, Liu Y, Cai S, He Y, Wu S and Song W: MicroRNA-215 suppresses cell proliferation, migration and invasion of colon cancer by repressing Yin-Yang 1. Biochem Biophys Res Commun 479: 482-488, 2016.

30. Jing X, Wu H, Ji X, Wu H, Shi M and Zhao R: Cortactin promotes cell migration and invasion through upregulation of the dedicator of cytokinesis 1 expression in human colorectal cancer. Oncol Rep 36: 1946-1952, 2016.

31. Merino D, Lok SW, Visvader JE and Lindeman GJ: Targeting BCL-2 to enhance vulnerability to therapy in estrogen receptor-positive breast cancer. Oncogene 35: 1877-1887, 2016.

32. Kvansakul M and Hinds MG: The Bcl-2 family: Structures, interactions and targets for drug discovery. Apoptosis 20: 136-150, 2015.

33. Feng W, Yoshida A and Ueda T: YM155 induces caspase-8 dependent apoptosis through downregulation of survivin and Mcl-1 in human leukemia cells. Biochem Biophys Res Commun 435: 52-57, 2013.

34. Sam MR, Ahangar P, Nejati V and Habibian R: Treatment of LS174T colorectal cancer stem-like cells with n-3 PUFAs induces growth suppression through inhibition of survivin expression and induction of caspase-3 activation. Cell Oncol (Dordr) 39: 69-77, 2016.

35. Chen X, Bode AM, Dong Z and Cao Y: The epithelial-mesenchymal transition (EMT) is regulated by oncoviruses in cancer. FASEB J 30: 3001-3010, 2016.

36. Petrova YI, Schecterson L and Gumbiner BM: Roles for E-cadherin cell surface regulation in cancer. Mol Biol Cell 27: 3233-3244, 2016.

37. Zhang J, Chen XY, Huang KJ, Wu WD, Jiang T, Cao J, Zhou LS, Qiu ZJ and Huang C: Expression of FoxM1 and the EMT-associated protein E-cadherin in gastric cancer and its clinical significance. Oncol Lett 12: 2445-2450, 2016.

38. Iseki Y, Shibutani M, Maeda K, Nagahara H, Ikeya T and Hirakawa K: Significance of E-cadherin and CD44 expression in patients with unresectable metastatic colorectal cancer. Oncol Lett 14: 1025-1034, 2017.
39. Sheng $\mathrm{L}$, Zhang $\mathrm{S}$ and $\mathrm{Xu} \mathrm{H}$ : Effect of slug-mediated down-regulation of E-cadherin on invasiveness and metastasis of anaplastic thyroid cancer cells. Med Sci Monit 23: 138-143, 2017.

40. Huang H, Svoboda RA, Lazenby AJ, Saowapa J, Chaika N, Ding K, Wheelock MJ and Johnson KR: Up-regulation of $\mathrm{N}$-cadherin by collagen I-activated discoidin domain receptor 1 in pancreatic cancer requires the adaptor molecule Shc1. J Biol Chem 291: 23208-23223, 2016.

41. Fernández NB, Lorenzo D, Picco ME, Barbero G, Dergan-Dylon LS, Marks MP, García-Rivello H, Gimenez L, Labovsky V, Grumolato L and Lopez-Bergami P: ROR1 contributes to melanoma cell growth and migration by regulating N-cadherin expression via the PI3K/Akt pathway. Mol Carcinog 55: 1772-1785, 2016.

42. Rabkin SW: Differential expression of MMP-2, MMP-9 and TIMP proteins in thoracic aortic aneurysm-comparison with and without bicuspid aortic valve: A meta-analysis. Vasa 43: 433-442, 2014.

43. Araújo RF Jr, Lira GA, Vilaça JA, Guedes HG, Leitão MC, Lucena HF and Ramos CC: Prognostic and diagnostic implications of MMP-2, MMP-9, and VEGF- $\alpha$ expressions in colorectal cancer. Pathol Res Pract 211: 71-77, 2015.

44. Guo JQ, Zheng QH, Chen H, Chen L, Xu JB, Chen MY, Lu D, Wang ZH, Tong HF and Lin S: Ginsenoside Rg3 inhibition of vasculogenic mimicry in pancreatic cancer through downregulation of VE-cadherin/EphA2/MMP9/MMP2 expression. Int J Oncol 45: 1065-1072, 2014.

This work is licensed under a Creative Commons Attribution-NonCommercial-NoDerivatives 4.0 International (CC BY-NC-ND 4.0) License. 